\title{
Measures of Underlying Inflation in Sri Lanka
}

Souvik Gupta and Magnus Saxegaard 


\title{
IMF Working Paper
}

Asia and Pacific Department

Measures of Underlying Inflation in Sri Lanka

Prepared by Souvik Gupta and Magnus Saxegaard

Authorized for distribution by Laura Papi

August 2009

\begin{abstract}
This Working Paper should not be reported as representing the views of the IMF. The views expressed in this Working Paper are those of the author(s) and do not necessarily represent those of the IMF or IMF policy. Working Papers describe research in progress by the author(s) and are published to elicit comments and to further debate.

During the first half of 2008, Sri Lanka witnessed significantly higher inflation than most other emerging Asian countries. Inflation has since declined amid declining world commodity prices and tight monetary policy. Given the sensitivity to global commodity prices, a core inflation measure could be useful for monetary policy. The purpose of this paper is to compare the performance of Sri Lanka's existing official measure of core inflation against alternative measures. Our findings suggest that the existing measure does contain information about the future path of headline information, but may be inadequate as a communication tool for the Central Bank.
\end{abstract}

JEL Classification Numbers:C50, E31, E52

Keywords: Core Inflation, Sri Lanka, Monetary Policy

Author’s E-Mail Address: sgupta2@imf.org; msaxegaard@imf.org 


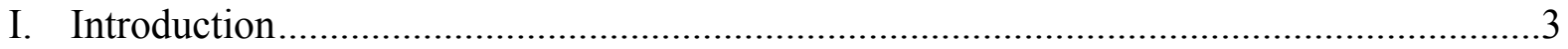

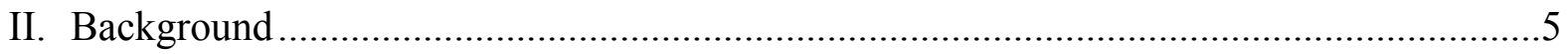

III. Alternative Measures of Core Inflation .........................................................................

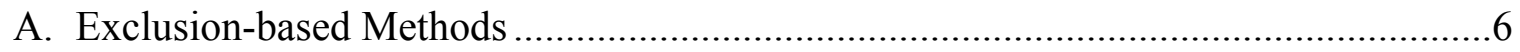

B. Limited Influence Estimators.............................................................................

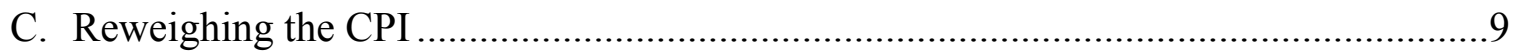

D. Model-based Methods.................................................................................... 10

IV. Conditions to Evaluate Measures of Core Inflation..................................................11

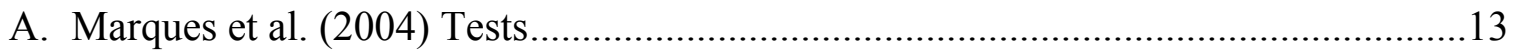

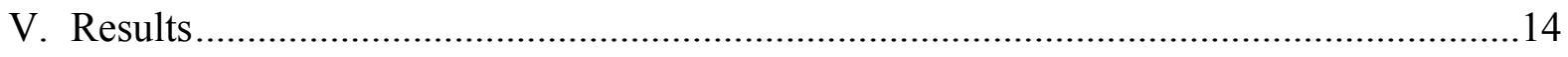

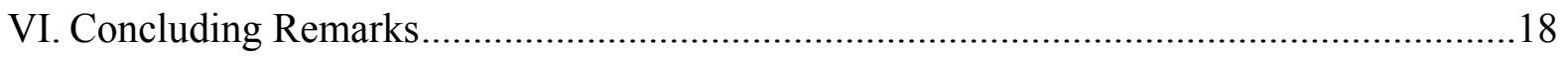

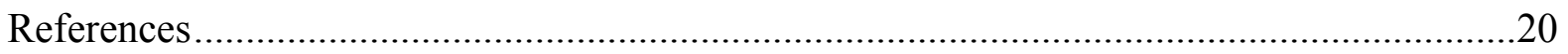

Figures

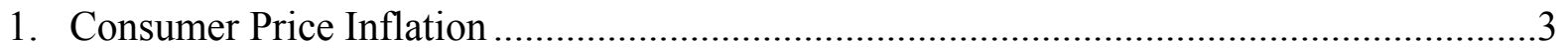

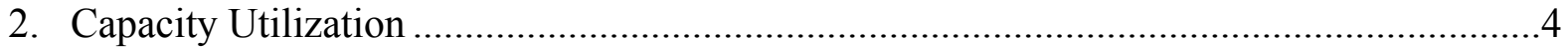

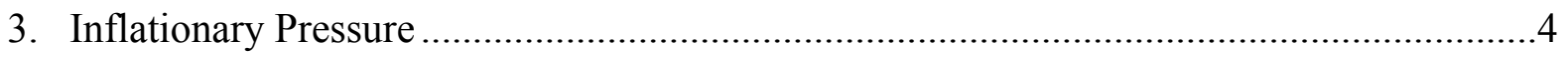

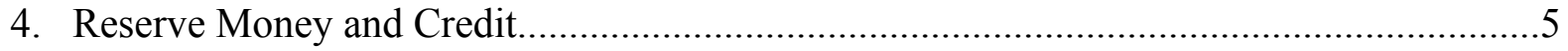

5. Exclusion Based Measure of Core Inflation .................................................................... 7

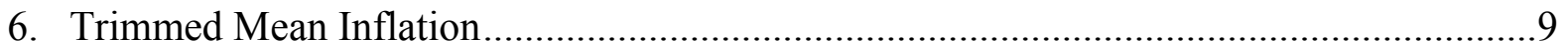

7. Root Mean Squared Errors of Alternative Trimmed Mean Measures ...............................9

8. Persistence Weighted Measure of Core Inflation ....................................................... 10

9. Quah-Vahey Measure of Core Inflation .............................................................. 12

Tables

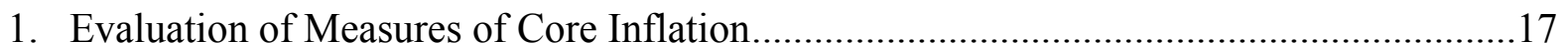




\section{INTRODUCTION}

The rapid rise in world commodity prices during 2008, most notably fuel and food prices, coincided with a sharp increase in inflation in Sri Lanka during the first half of the year. Inflation in Sri Lanka has mostly stayed in the double digits over the past five years and averaged nearly 20 percent during 2007-08, far exceeding the inflation rates observed in other countries in the region (Figure 1). Notwithstanding the high and rising headline inflation during the first half of 2008, the Central Bank of Sri Lanka (CBSL) had argued that the then prevailing relatively low level of the existing measure of core inflation (official core inflation), introduced in April 2008, was an indication of the success of monetary policy in Sri Lanka at containing the underlying inflation and that once the world commodity price shocks died out, headline inflation would decline to levels

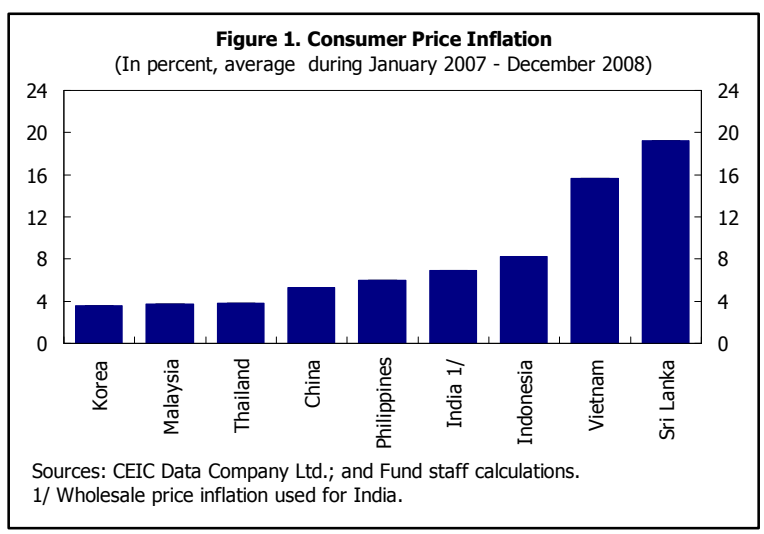
closer to that of core inflation. Though both headline and official core inflation have eased off significantly over the past few months, the latter has been higher than the former since November 2008.. The purpose of this paper is to contribute to the ongoing debate at the CBSL about the appropriate measure of core inflation by evaluating the official measure of Sri Lanka's core inflation - constructed by excluding all food and fuel prices from the consumer price index (CPI) - by comparing it to alternative measures of core inflation that have been proposed in the literature ${ }^{1}$.

The popularity of core inflation measures among policy makers derives from numerous weaknesses in the CPI which detract from its usefulness as a measure of inflation for monetary policy purposes. Firstly, there is an important conceptual issue: the CPI measures the cost of attaining the same standard of living - the same basket of goods - today as in a reference period. However, the primary role of monetary policy is not to stabilize the cost of living but to create the conditions for the price mechanism to function effectively as a signal of relative scarcities in a market economy. Secondly, seasonal influences, indirect taxes, and changes in the relative price of goods affect the CPI, but do not warrant a monetary policy response, while interest payments - which also affect the CPI - are a tool, rather than a goal, of monetary policy. Finally, there is the issue of control: in the short run, CPI inflation is the product of nearly every shock hitting the economy, while monetary policy only affects CPI inflation with a considerable lag. It would therefore be interesting for policy makers and the public to have a measure of inflation which: (i) is a leading indicator of CPI inflation; and (ii) strips out movements in prices due to transitory shocks over which the monetary authorities have no control.

\footnotetext{
${ }^{1}$ This paper uses data provided by the Central Bank of Sri Lanka on the 32 components of the new Colombo consumer price index $(2002=100)$ for the period of January 2003 to October 2008.
} 

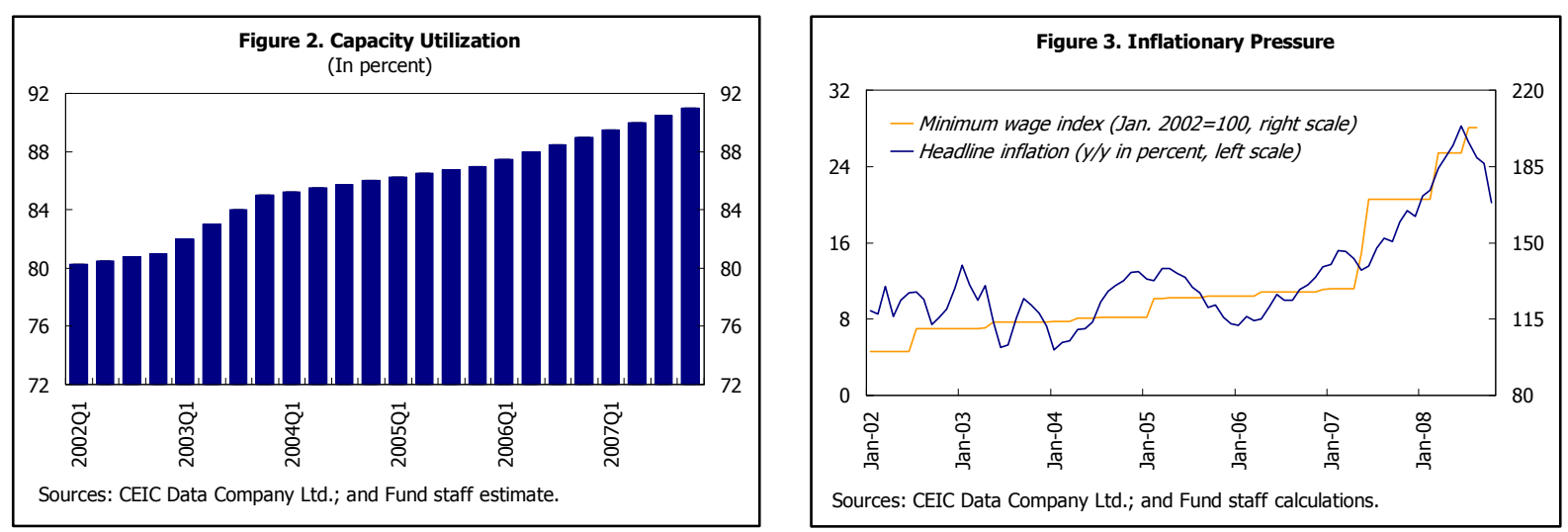

A range of methodologies have been proposed in the literature to measure core inflation. As Wynne (2008) points out, the proposed methods are based either on cross-sectional information, or on time series or pooled cross-sectional and time series data. Methods based on the former attempt to refine the CPI by excluding volatile or transitory components, while the latter include time series methods aimed at removing high-frequency noise and econometric models that attempt to decompose the CPI into a core and non-core part. Heath et al. (2004) provide an exhaustive analysis of 102 different measures of core inflation-after putting aside the less-likely measures - using Australian data, illustrating how the alternative approaches can provide quite different results. This paper provides an analysis of core inflation for Sri Lanka estimated using some of the more popular methods and how they compare to the authorities' exclusion-based measure.

A set of criteria or tests have also been proposed in the literature to assess the performance of the various measures of core inflation. A practical problem with these tests is that there is no consensus on the properties of core inflation. Some authors (inter alia Roger, 1998; and Wynne, 2008) emphasize the importance of the credibility of a core inflation measure, in particular when used as an inflation target, while others emphasize the importance of unbiasedness and predictive ability (see for example, Marques et al., 2000 and 2003; Bryan and Cecchetti, 1993; and Mankikar and Paisley, 2004). In addition, Silver (2007) argues that different methods for estimating core inflation are designed for different purposes and thus that no single measure should be expected to meet every criteria. As a result there is little unanimity in the literature as to what is the best measure, with conclusions varying according to the country and the time-period analyzed. Indeed numerous authors (see Roger, 2000; Heath et al., 2004; Mankikar and Paisley, ibid.; and Silver, ibid) argue that the emerging consensus is that a suite of measures should be employed by policy makers. As Silver (ibid.) notes: "If the resulting measures give similar results, then they should give some confidence to the monetary authorities in making decisions based on such measures."

The remainder of this paper is organized as follows. Section B provides a brief review of recent monetary developments in Sri Lanka with a focus on the movements of official core and CPI (headline) inflation. Section $\mathrm{C}$ briefly reviews some of the problems with using headline inflation for policy purposes before discussing the concept and alternative meanings of core inflation applying them to Sri Lankan data. Section D outlines performance evaluation techniques for core inflation and section $\mathrm{E}$ applies these techniques to the various 
measures of core inflation in the Sri Lankan context. Finally, a section concludes with some thoughts on the implications for monetary policy in Sri Lanka.

\section{BACKGROUND}

Inflation in Sri Lanka increased rapidly from the second half of 2007, peaking at 28.2 percent year-on-year in June 2008 (as measured by the new Colombo CPI) before dropping below double digits in February 2009 for the first time in more than two years. These sharp movements in headline inflation can largely be attributed to the weight of food and fuel prices in the reference consumption basket and to the extent to which world commodity prices are passed through to consumers in Sri Lanka - food and fuel price inflation on average accounted for 73 and 8 percent of overall CPI inflation in 2008-although evidence of capacity constraints and rising wages during 2008 suggested that demand pressures were also important.

With the authorities' official measure of core inflation staying in double digits during the second half of 2008, the Central Bank of Sri Lanka (CBSL) noted that the historically high commodity prices in 2008 likely had significant second round effects on other components of the consumption basket. ${ }^{2}$ The CBSL restrained the expansion of reserve money in 2008 when it became clear that the high headline inflation was having second round effects. The target growth rate of reserve money was revised downward from 15 to 9.7 percent in three steps between April and November, 2008. In the event, reserve

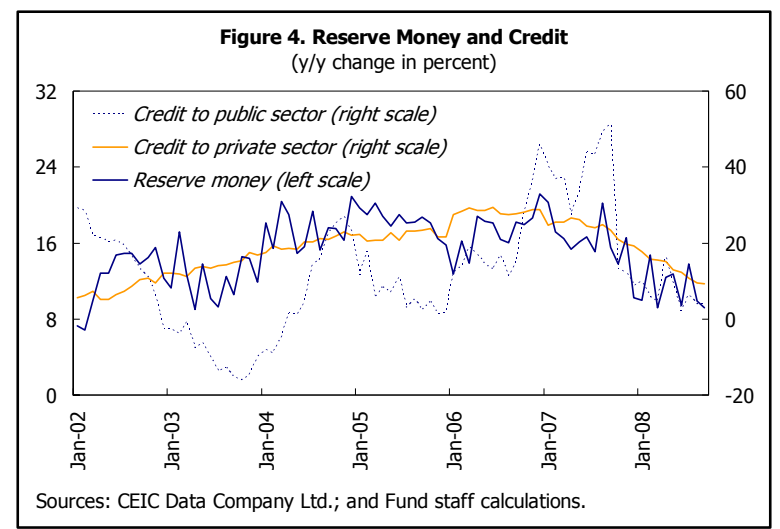
money in 2008 grew at an annual rate of 1.5 percent relative to 21.2 percent in 2006 (Figure $4) .^{3}$

In its April 2008 Monetary Policy Review statement, the CBSL argued that the moderate core inflation - coupled with the deceleration in aggregate demand - was an indication of the success of the demand management policies of the Central Bank. It further argued that as the shock to world commodity prices died down, the gap between headline and core inflation should gradually diminish. Although not stated explicitly, it was implied that headline inflation would gradually decline toward core inflation and therefore that the official measure of core inflation in Sri Lanka was a leading indicator of future headline inflation. In the event, headline inflation has declined dramatically to below 1 percent on a year-on-year basis and the consensus is that inflationary pressures are low. Moreover, it has remained below the

\footnotetext{
${ }^{2}$ Monetary Policy Review_July 2008.

${ }^{3}$ Large-scale intervention in support of the rupee during the last four months of 2008 largely explains the short fall of reserve money growth relative to target.
} 
official measure of core inflation since November, 2008, thereby raising questions about its usefulness as a leading indicator of headline inflation ${ }^{4}$ In order to accurately address this question, the remainder of this paper evaluates the official measure of core inflation and compares it to other measures that have been proposed in the literature.

\section{Alternative Measures of Core Inflation}

In spite of the rising popularity of core inflation in the conduct of monetary policy, there is no consensus in the literature on a definition of core inflation. Bryan and Cecchetti (1993) have suggested that core inflation reflects price changes attributable to the growth rate of the money supply. Underlying this view is the notion that in the long-run, inflation is a monetary phenomenon. Blinder (1997) and Marques et al. (2003) identify core inflation as the persistent or durable component of inflation, while Quah and Vahey (1995) define core inflation as the component of measured inflation that has no medium to long-run impact on real output.

Added to this, Mankikar and Paisley (2004) and Silver (2007) identify two different uses for core inflation. The first is to provide a measure of inflation stripped of noise to provide a measure of actual inflation for policy assessment. The second is to provide an estimate of future inflation and thus of the underlying pressures in the economy. Given the lags in the monetary transmission mechanism, a leading indicator of future headline inflation is particularly useful for the formulation of policy.

We examine a range of different methods, starting with exclusion-based methods and limited influence estimators, both of which are based on cross-sectional information, before considering measures based on reweighing the CPI and the estimation of economic models which rely on time series data.

\section{A. Exclusion-based Methods}

The most popular method for constructing core inflation is to exclude components of the CPI that are considered to be too volatile (for example, seasonal food and energy prices) or which do not warrant a monetary policy response (for example, indirect taxes or mortgage interest payments). The new official core inflation in Sri Lanka is an example of an exclusion based measure which excludes all food and energy prices, with a cumulative weight of 54.6 percent in the CPI.

\footnotetext{
${ }^{4}$ While headline inflation was 1.7 percent below the official core inflation in November 2008, the gap widened to 10.2 percent four months later, before narrowing to 4.9 percent in July 2009 .
} 
The benefit of exclusion-based methods derives from their simplicity. Also, unlike limited influence estimators considered below, the components of core inflation are unchanged every period, so one is considering like for like over time. However, as Mankikar and Paisley (2004) point out, this comes at the cost of assuming that some components' price changes contain no information at all about underlying

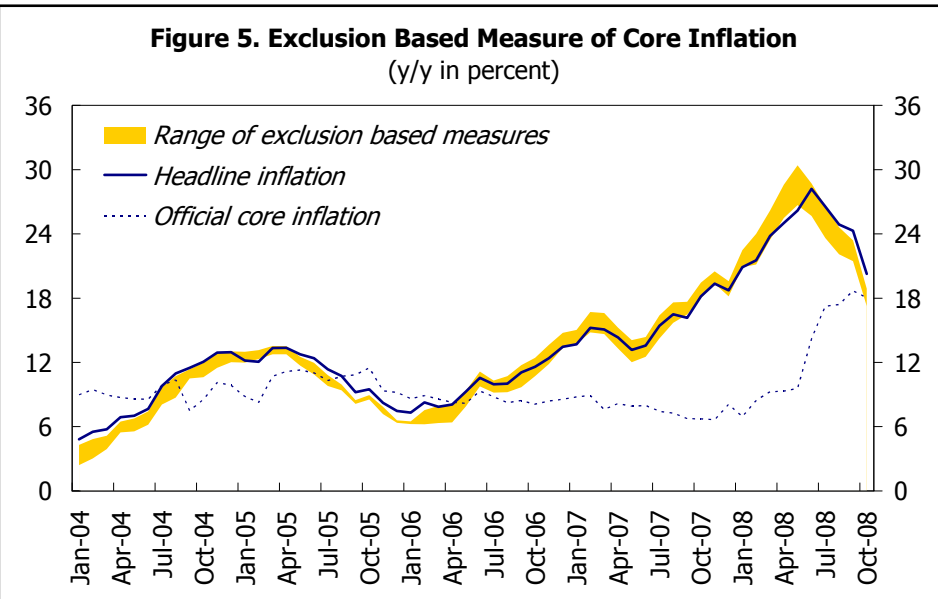

Sources: Central Bank of Sri Lanka.; and Fund staff estimates. inflation and do not add to the information set of policy makers.

When exclusion based measures are used, Silver (2007) notes that the criteria for exclusion need to be transparent or relatively standard to ensure that the central bank is not perceived to be manipulating core inflation. In Canada, for example, the eight most volatile components of the CPI based on historical data were excluded (Macklem, 2001). However, in many countries - including Sri Lanka — all food is excluded from the CPI although not all categories of food exhibit seasonal patterns nor are particularly volatile. In addition, excluding all food items may detract from the credibility of the core inflation measure in developing countries where food may be the dominant component of expenditure among poorer members of the society (Lehohla and Myburgh, 2002).

Figure 5 plots CPI inflation together with the authorities' exclusion-based measure of core inflation and alternative measures constructed by excluding the volatile components of the CPI based on annualized monthly inflation data from January 2004 to October 2008. ${ }^{5}$ The alternative exclusion-based measures suggest that core inflation was between 17.3 percent and 18.9 at end-October compared to 18 percent in the authorities' official measure. However, the difference between the official measure and the alternative exclusion based measures was significantly higher between late 2006 and September 2008, a period highlighted by high and volatile food and fuel prices. The reason for this difference is the exclusion of the food component in the authorities' measure (45.5 percent weight in CPI), whereas inclusion of the same in our measure as food inflation turns out to be one of the less volatile components (out of a total of 32 commodity groups) in the CPI.

\footnotetext{
${ }^{5}$ The authorities' measure of core inflation excludes food, electricity, gas, kerosene, firewood, petrol and other fuels with a combined weight of 54.6 percent. The alternative volatility based measures use the standard deviation of the month-on-month price changes and exclude the most volatile 10, 20, 30 and 40 percent items in a cross-section of 32 commodity groups. None of these measures include food items. The cumulative weight of the excluded items varied from 4.8 percent for a measure based on excluding 3 most volatile items (the 10 percent measure) to 22.32 percent for a measure based on excluding 12 most volatile items (the 40 percent measure).
} 


\section{B. Limited Influence Estimators}

Limited influence or trimmed mean estimators are based on trimming the outlying portions of the cross-sectional distribution of the components of the CPI. More generally, the median is one example of a limited influence estimator which trims 50 percent from each tail. Bryan and Cecchetti (1993) have justified trimming on the grounds that the extremes of the distribution of price changes are likely to contain less information about underlying price pressures than the centre of the distribution. The extremes of the distribution might reflect seasonality or other noises, but also relative price movements that can affect the inflation rate because prices are not completely flexible in the short and medium term.

As noted by Silver (2007), limited-influence estimators benefit from being timely, transparent, and easy to replicate. However, as Mankikar and Paisley (2004) point, they are not without problems. For example, assume that in response to an increase in aggregate demand, only a portion of firms raise prices while the remainder leave their prices unchanged. A trimmed mean estimator in this case would yield a core inflation rate of zero which clearly gives a misleading picture of underlying inflation. In this case, the tails of the distribution of price changes contain more information than the center.

Another problem with trimmed mean estimators is that they are found to yield estimates of core inflation that are systematically lower than CPI averages, implying that the trimming is doing more than just removing random shocks (see Kearns, 1998; and Cutler, 2001). As Roger (2000) points out, this is not surprising given that the distribution of price changes, especially in developing and emerging market countries, are typically skewed to the right. We find that Sri Lanka is no exception in this regard. This suggests using an asymmetric trim which removes more of the left-hand portion of the distribution so that the mean is pulled upward.

The decision about how much of the distribution of price changes should be trimmed, and whether the trim should be symmetric or not, is clearly an important one. Following Cecchetti (1997), it has become popular in the literature to choose a trim which minimizes the root mean square error (RMSE) with respect to the 37-month centered moving average of headline inflation. However, as Mankikar and Paisley (2004) point out, there is no a priori reason to assume that this is a sensible benchmark for any given country. It has been argued that it possesses the benefit of being smooth, but if the underlying aggregate demand shocks hitting the economy are not smooth or if the transmission of these shocks is changing, then underlying inflation would not be expected to be smooth either.

Figure 6 plots a range of symmetric and asymmetric measures of core inflation for Sri Lanka Given the skewness of the distribution of price changes in Sri Lanka, an asymmetric trimmed mean measure results in a lower RMSE compared to symmetric trim measures. In particular, trimming 20 percent of the left tail and 5 percent of the right tail yielded the lowest RMSE (see Figure 7). Estimates for core inflation in October-2008 ranged from 15.4 percent to 16.0 percent for symmetric trims and from 9 to 22.6 percent for asymmetric trims. The 
inflation rate was at 20.6 percent according to the trimmed mean measure with the least RMSE $^{6}$.
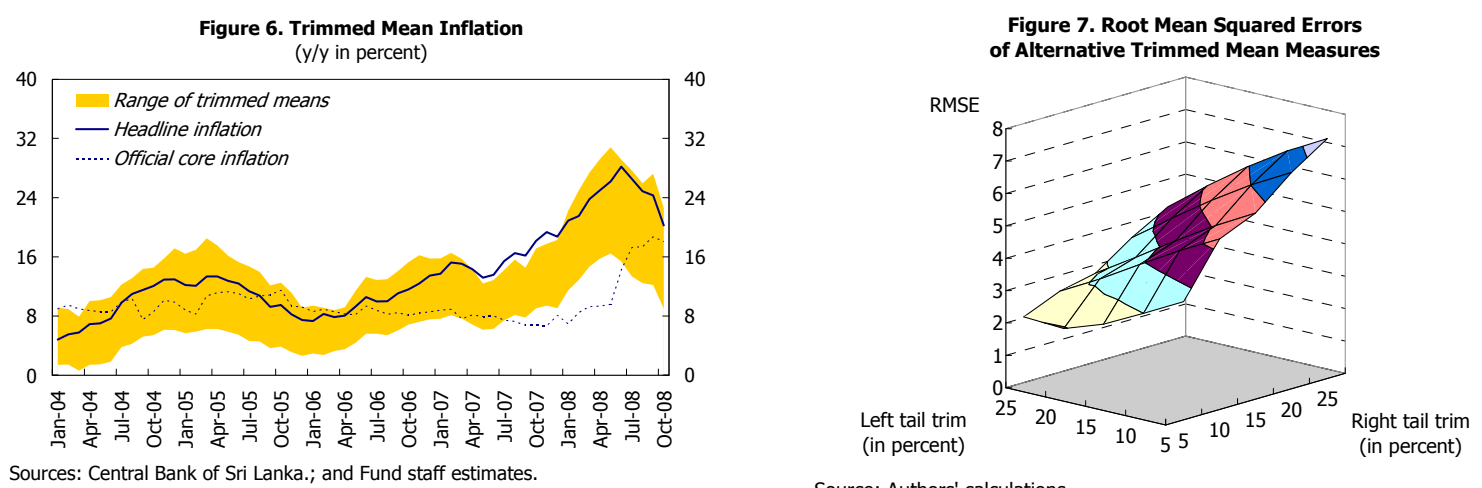

C. Reweighing the CPI

Another approach to measuring core inflation reweighs the components of the CPI according to the signal each component provides about underlying inflation. One popular way of doing this is due to Blinder (1997) who identified core inflation with the durable or persistent component of inflation and suggested that more weight be given to components considered to contain information about future inflation. This methodology was operationalized by Cutler (2001) who obtained the weights by estimating an autoregressive model for each component of the CPI. In this paper, we use the following AR(1) model for month-on-month inflation

$$
\pi_{i}^{t}=\alpha_{i}+\rho_{i} \pi_{i}^{t-1}+\varepsilon^{t}
$$

Where $\pi_{i}^{t}$ is month-on-month inflation at time period $t$ and estimate of $\rho_{i}$ is the indicator of persistence of inflation in each commodity group $i$. Product groups with negative autocorrelation are assigned a weight of zero in the calculation of core inflation. The persistence weighted index is then given by the following:

$$
\frac{\sum_{i \in \rho_{i}>0} \hat{\rho}_{i} \pi_{i}^{\prime}}{\sum_{i \in \rho_{i}>0} \hat{\rho}_{i}}
$$

The approach may be refined by including further lags in equation (1) or by using different weights every year estimated recursively.

Despite the benefit of focusing on the durable components of inflation for the purpose of predicting future headline inflation, the methodology has its limitations. Mankikar and Paisley (2004) note that it is subject to the Lucas critique: the autoregressive coefficients will

\footnotetext{
${ }^{6}$ Our ability to use a finer grid to find the lowest RMSE was constrained by the low cross-sectional dimension of the Sri Lankan data.
} 
in part depend on past policy. However, if policy-makers were to factor these weights into their decisions, the weights would change and the measure of core inflation would become misleading. Silver (2007) also notes that because it is relatively complex, a persistenceweighted measure of core inflation could suffer from a lack of transparency and thus credibility.

Figure 8 plots a persistenceweighted measure of core inflation using weights estimated in equation (1) - an AR(1) model of month-on-month inflation for the period February 2003 to October 2008. This measure suggests that core inflation was 33.6 percent in October 2008.

\section{Model-based Methods}

Model based measures of core

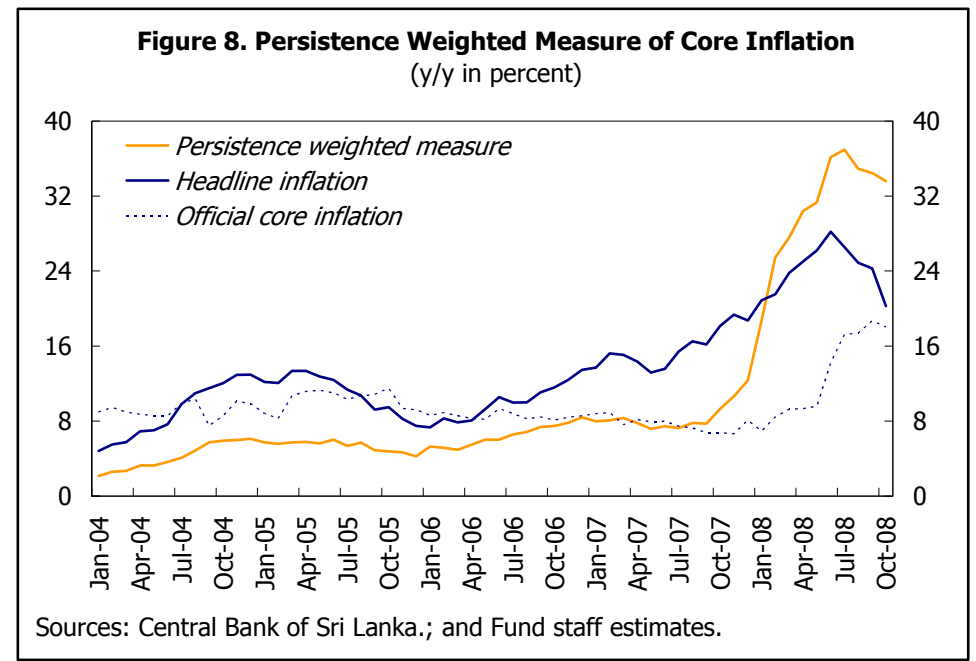
inflation benefit from being grounded in economic theory. They therefore explicitly give some economic interpretation to the underlying process of core inflation and to deviations between headline and core inflation. Model based measures also benefit from being multivariate and thus take advantage of potentially relevant information from other variables to derive core inflation.

Unfortunately there is no consensus about the theoretical properties of core inflation. Eckstein (1981) argues that core inflation is equivalent to "...the trend increase of the cost of the factors of production." The implication is that core inflation should not be cyclical. Quah and Vahey (1995) on the other hand, define core inflation as "...that component of measured inflation that has no medium to long-term impact on real output". Implicit in their model is the notion of a vertical long-run Phillips curve. In other words, core inflation is assumed to be output-neutral in the long run once financial and wage contracts have been updated. In the short-run, however, nominal rigidities ensure that there will be short-run trade-off between (both core and non-core) inflation and output.

In addition to the lack of consensus concerning the correct model, model-based measures of core inflation have been criticized on the grounds that each time new data becomes available, historical data on core inflation will have to be revised. In addition, model-based estimates of core inflation are not easy to understand and typically hard to replicate. Because of these issues, model-based measures may lack credibility with the public.

Following Quah and Vahey (1995) we can write the (logarithm) of economic activity (Y) and measured inflation $(\pi)$ as:

$$
X_{t}=A(0) \eta_{t}+A(1) \eta_{t-1}+\ldots .=\sum_{k=0}^{\infty} A(k) \eta_{t-k}
$$


where $X=(\Delta Y, \Delta \pi)^{\prime}$ and $\eta=\left(\eta_{1}, \eta_{2}\right)^{\prime}$. The two disturbances $\eta_{1}$ and $\eta_{2}$ are assumed to be pairwise orthogonal with $\operatorname{Var}(\eta)=I$. While the two disturbances can influence measured inflation, their impact on economic activity differs. In particular, $\eta_{1}$ is assumed to have no impact on economic activity in the medium-to-long term. This long run neutrality condition can be summarized as $\sum_{k=0}^{\infty} a_{11}(k)=0$ : the upper left hand entries of the sequence of matrices $A$ sum to zero. Measured inflation can then be decomposed as follows:

$$
\Delta \pi_{t}=\sum_{k=0}^{\infty} a_{21}(k) \eta_{1}(t-k)+\sum_{k=0}^{\infty} a_{22}(k) \eta_{2}(t-k)
$$

Core inflation is then defined as the process $\sum_{k=0}^{\infty} a_{21}(k) \eta_{1}(t-k)$ or, in other words, the movement in measured inflation associated with shock $\eta_{1}$ which has the characteristic that it is output neutral in the long run.

To recover the above representation from the data, a vector autoregression (VAR) is estimated and inverted to yield the Wold moving average representation of $X=(\Delta Y, \Delta \pi)^{\prime}$. Assuming that the underlying disturbances $\eta_{1}$ and $\eta_{2}$ are linear combinations of the Wold innovations obtained from estimating the VAR above, one can uniquely recover $\eta_{1}$ - the disturbance influencing the core inflation - under certain restrictions that makes the matrix $A(0)$ unique. $^{\top}$

Figure 9 shows the Quah and Vahey measure of core inflation for Sri Lanka. ${ }^{8}$ The results suggest that core inflation reached 23.7 percent in September 2008 while headline inflation was 24.3 percent.

\section{Conditions to Evaluate Measures of Core Inflation}

Having derived different measures of core inflation for Sri Lanka, we now turn to assessing their usefulness and to a discussion about how to choose among the different measures. As Ginting (2007) notes, a core inflation measure should meet a number of practical as well as statistical criteria.

\footnotetext{
${ }^{7}$ Three such restrictions come from imposing that $A(0) A(0)^{\prime}=\Omega$, where $\Omega$ is the variance-covariance matrix of the Wold innovations and where $A(0)$ is retrieved from the cholesky decomposition of the matrix $\Omega$. The fourth restriction is the long-run output neutrality condition.

${ }^{8}$ Estimated using monthly data for headline inflation and the industrial production index (as a proxy for economic activity) over the period March 2004 to October 2008.
} 
In terms of practical considerations, Roger (1998) argues that a core inflation measure should be: (i) timely; (ii) credible (verifiable by independent observers); (iii) easily understood by the public; and (iv) not significantly biased with respect to the targeted measure (headline inflation in the case of Sri Lanka). Additional criteria that have been proposed include the requirement that core inflation should: (i) be computable in real

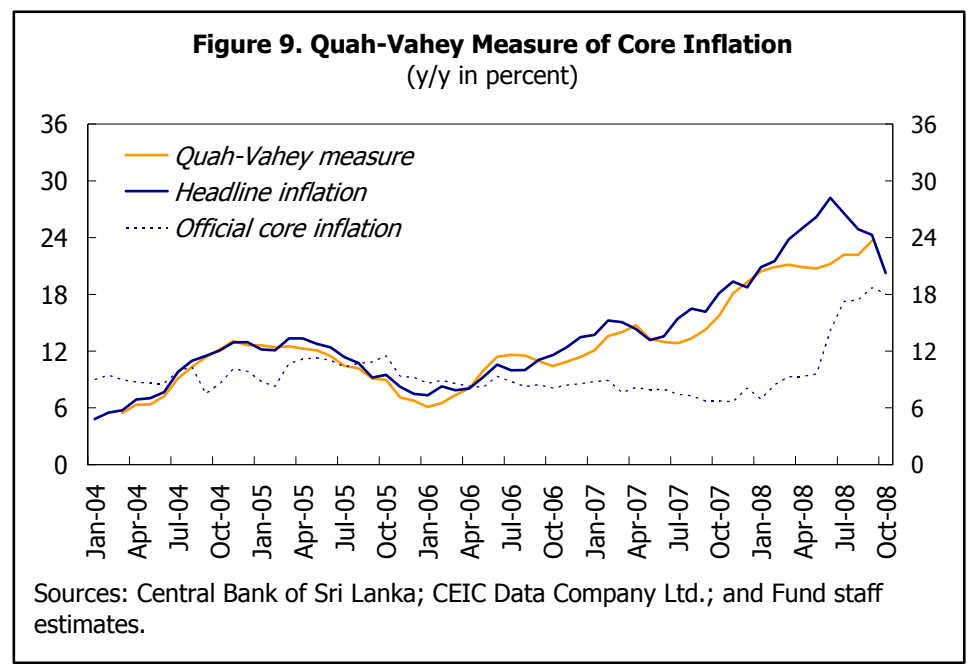
time; (ii) be forward looking; (iii) have some theoretical basis; and (iv) not be subject to revisions.

It should be clear from the discussion in the previous section that none of the measures proposed in this paper satisfy all of these criteria. However, as Silver (2007) notes, policy makers will attach different weights to these criteria depending on the purpose of the core inflation measure. If the purpose is to allow the public to assess the conduct of monetary policy then timeliness, credibility, simplicity, unbiasedness, and not being subject to revisions would be important. Exclusion-based estimators and limited influence estimators of core inflation might be suitable in this case. If the purpose is to guide monetary policy decision-making then it is more important that core inflation be forward-looking and perhaps have some theoretical basis. Model-based estimators and methods which reweigh the CPI would seem appropriate here.

However, numerous empirical studies have shown that there is no guarantee that any given measure of core inflation will achieve the purpose they were designed for. Moreover, as noted in the introduction, the assessment of different measures varies according to the country and the time-period analyzed. As Silver (2007) notes, this implies that the ultimate choice of method should be data-driven and based on statistical criteria in order to reflect the particular circumstances of each country. The remainder of this section discusses some of these statistical criteria and the tests for unbiasedness, cointegration, and causality proposed by Marques et al. (2003). ${ }^{9}$

\footnotetext{
${ }^{9}$ Other authors, including Silver (2007) and Ginting (2007) have emphasized the importance of volatility as a criteria. However, as noted earlier, there is no a priori reason to expect that core inflation should be particularly smooth if demand shocks are important or if the transmission of these shocks to the economy is changing. It should be noted, however, that all of the measures surveyed here have significantly lower volatility than headline inflation.
} 


\section{A. Marques et al. (2004) Tests}

Marques et al. (2000) argue that an appropriate measure of core inflation should possess the characteristic that headline inflation converges to core inflation in the long run but not vice versa. For a measure of core inflation to satisfy this criteria it must be the case that headline and core inflation are cointegrated with unit coefficient (condition (i)). In other words, the difference between headline and core inflation, $u_{t}=\pi_{t}-\pi_{t}^{*}$ should be stationary with a mean of zero. If $u_{t}$ were not stationary, headline and core inflation would tend to diverge in the long-run. If mean of $u_{t}$ were not zero, core inflation would not be capturing the persistent component of headline inflation and would be biased..$^{10}$

Following Marques et al. (2003) we test condition (i) in two stages. In the first stage, we test whether or not $u_{t}=\pi_{t}-\pi_{t}^{*}$ is a stationary process where $\pi_{t}$ is the year-on-year rate of change of the headline CPI and $\pi_{t}^{*}$ is the year-on-year change in the different core indices. Given that it is well-know that the Augmented Dickey Fuller (ADF) test does not have much power, we also report results from the KPSS test (Kwiatkowski et al., 1992) which, contrary to the ADF test, has a null hypothesis of stationarity. In each case, the tests are carried out by including a constant. In the second stage, we test whether $u_{t}=\pi_{t}-\pi_{t}^{*}$ has mean of zero by testing the significance of the constant term using a simple $t$-test.

For a measure of core inflation to satisfy the criteria set out by Marques et al. (2003) it must also be true that core inflation is an attractor of headline inflation (condition (ii)), and conversely that headline inflation is not an attractor for core inflation (condition (iii)). From Granger's representation theorem (Engle and Granger, 1987) we know that if condition (i) holds then there exists an error correction representation for headline and/or core inflation. Condition (ii) requires that such a representation exist for headline inflation and implies that if headline inflation is above core inflation, then we can expect that headline inflation will sooner or later start to decrease and will converge to core inflation. In other words, condition (ii) requires that core inflation Granger causes headline inflation through the error-correction term and thus is a leading indicator for headline inflation. Formally, we test condition (ii) by estimating the following error-correction model for $\pi_{t}$ :

$$
\Delta \pi_{t}=\sum_{j=1}^{m} \alpha_{j} \Delta \pi_{t-j}+\sum_{j=1}^{n} \beta_{j} \Delta \pi_{t-j}^{*}-\gamma\left(\pi_{t-1}-\pi_{t-1}^{*}\right)+\varepsilon_{t}
$$

and testing whether the null hypothesis of $\gamma=0$ is rejected.

\footnotetext{
${ }^{10}$ A number of authors, including Heath et al. (2004) consider that unbiasedness is an essential property of core inflation. As Ginting (2007) notes, a significant deviation in the unconditional means of core and headline inflation would undermine the claim that core inflation represents the underlying trend of inflation and thus the credibility of the core measure.
} 
As Marques et al. (2003) point out, condition (ii) should not be interpreted as a test of the ability of core inflation to forecast future inflation. Condition (ii) simply requires that, by virtue of it being an attractor, core inflation possesses some information about future headline inflation. In fact, contrary to Freeman (1998) and Le Bihan and Sédillot (2000), Marques et al. (ibid.) argue that we should not expect core inflation to be a good forecast of future headline inflation. A good forecast should be able to predict future short-term movements in headline inflation, but this is not a characteristic we typically expect core inflation-which they argue is simply a summary of the long-run characteristics of inflation - to have.

Condition (iii) requires that an error correction representation does not exist for core inflation. In other words, headline inflation should not be an attractor for core inflation. With reference to the example in the previous paragraph, it would only be possible to predict that headline inflation would decline toward core inflation if the future path of core inflation is not a function of headline inflation, as required by condition (iii). The condition that headline inflation is not an attractor for core inflation is equivalent to core inflation being exogenous. As in Marques et al. (ibid.) we test both for weak exogeneity $(\lambda=0)$ and strong exogeneity $\left(\theta_{1}=\ldots=\theta_{j}=0\right.$ given $\left.\lambda=0\right)$ in the following equation:

$$
\Delta \pi^{*}{ }_{t}=\sum_{j=1}^{r} \delta_{j} \Delta \pi_{t-j}^{*}+\sum_{j=1}^{s} \theta_{j} \Delta \pi_{t-j}^{*}-\lambda\left(\pi_{t-1}^{*}-\pi_{t-1}\right)+\eta_{t}
$$

The test for strong exogeneity is carried out by re-estimating equation 6 with the restriction $\lambda=0$ for the measures of core inflation that are weakly exogenous.

We now turn to the discussion of the results of application of these tests to the official and alternative core inflation measures for Sri Lanka.

\section{RESUlts}

This section evaluates the official measure of core inflation as well as the alternative measures constructed previously for Sri Lanka on the basis of the tests proposed above. ${ }^{11}$ The empirical results are presented in Table $1 .^{12}$

The first two columns of Table 1 reports the results from the ADF and the KPSS tests for the stationarity of $u_{t}=\pi_{t}-\pi_{t}^{*}$. Unsurprisingly, the low power of the ADF test implies that, with the exception of the Trimmed Mean 25L10R measure of core inflation, we are unable to reject the null hypothesis of no cointegration with headline inflation in any of the series at the 5 percent level. However, the KPSS test, which has a null hypothesis of stationarity

\footnotetext{
${ }^{11}$ ADF tests suggest that both headline and the different core inflation series are I(1) without drift as required for the Marques et al. (2003) tests to be valid.

${ }^{12}$ For the sake of brevity, we report a subset of the core inflation measures discussed previously on the basis of their RMSE.
} 
(cointegration), suggest that the Quah-Vahey measure, the Trimmed Mean 25L10R measure, the Persistence Weighted measure and both alternative exclusion based measures are cointegrated with headline inflation. Overall, the two tests strongly suggest that the official core measure, the Trimmed Mean 15L5R measure, the Trimmed Mean 20L5R measure, and the Trimmed Mean 25L5R measure are not cointegrated with headline inflation and thus are unlikely to converge to the same trend as headline inflation in the long run. Conversely, the tests strongly suggests that the Trimmed Mean 25L10R measure is cointegrated with headline inflation.

The third and the fourth column in Table 1 report the results from a simple $t$-test for whether the constant term in the ADF and the KPSS regressions are significantly different from zero. As noted previously, this amounts to testing whether a measure of core inflation is an unbiased measure of underlying inflation. As was the case in the previous section, the low power of the ADF test implies that the null hypothesis that the constant term is significantly different from zero cannot be rejected for any of the measures of core inflation. By contrast, the KPSS test rejects the null hypothesis in every case except the Trimmed Mean 15L5R and the Exclusion 3 measure. We conclude, therefore, that only these two measures of core inflation can be considered unbiased estimators of core inflation.

The fifth column reports the results of the test for condition (ii) which stipulates that in the long run, headline inflation should converge to core inflation. As noted previously, this amounts to a test for the significance of $\gamma$ in equation 5. The results suggest that the null hypothesis of $\gamma=0$ is rejected for the official measure of core inflation, the Trimmed Mean 25L10R measure, and both exclusion based measures. In other words these measures of core inflation are attractors of headline inflation and thus satisfy condition (ii).

The sixth column reports the results for the first part of condition (iii), namely that $\lambda=0$ in equation 6 and thus that core inflation is weakly exogenous for the parameters of the cointegrating vector in equation 6 . Our results suggest that this condition is satisfied for all the measures of core inflation with the exception of the Trimmed Mean 25L10R measure and the Exclusion 6 measure. The last column of Table 1 reports the results of the second part of condition (iii), namely that $\left(\theta_{1}=\ldots=\theta_{j}=0\right.$ given $\left.\lambda=0\right)$ in equation 6 . Among the weakly exogenous estimators of core inflation, the null hypothesis of strong exogeneity is only rejected in the case of the Persistence Weighted measure of core inflation.

The results suggest that the official measure of core inflation and the Exclusion 3 measure are leading indicators of headline inflation, but not vice versa. In other words the results indicate that these measures provide a useful guide for the future path of headline inflation. In the case of the Quah Vahey measure, the Trimmed Mean 15L5R measure, the Trimmed Mean 20L5R measure, the Trimmed Mean 25L5R, and the Persistence Weighted measure, the results suggest that no error correction representation exists for either headline or core inflation, suggesting that these measures are not cointegrated with headline inflation. In the case of the Trimmed Mean 15L5R measure, the Trimmed Mean 20L5R measure, and the Trimmed Mean 25L5R, this tallies well with our results from both the ADF and the KPSS tests. Overall, our results confirm that the appropriate measure of core inflation depends on its purpose. 
When interpreting the results of these tests, however, a few caveats need to be borne in mind. Mankikar and Paisley (2004) note that if the authorities successfully target headline inflation, then inflation would remain close to target with deviations only due to unforecastable errors. In this case, any measure of core inflation would fail conditions (ii) and (iii). This follows straightforwardly from the Granger representation theorem: because in this scenario no error correction representation exists for headline inflation, it must be the case that one exists for core inflation. In other words, headline inflation would not be attracted to core inflation because it follows an exogenously prescribed target, but core inflation would be attracted to headline inflation. However, this does not mean that core inflation measures are not informative for policy purposes, it is just that Marques et al.'s tests do not enable us to make that judgment. In addition, Mankikar and Paisley (2004) note that Marques et al's tests are subject to the Lucas critique: if future policy is based on some estimated relationship between core and headline inflation, that relationship is likely to break down and become misleading. 
Table 1. Evaluation of Measures of Core Inflation

\begin{tabular}{|c|c|c|c|c|c|c|c|}
\hline \multirow[t]{3}{*}{ Methodology } & \multicolumn{4}{|c|}{ Cointegrated with unit coefficient } & \multirow{3}{*}{$\begin{array}{c}\text { Core inflation an } \\
\text { attractor for } \\
\text { headline inflation 1/ } \\
\qquad \mathrm{Y}=0\end{array}$} & \multicolumn{2}{|c|}{$\begin{array}{l}\text { Headline inflation not an attractor } \\
\text { for core inflation } 1 /\end{array}$} \\
\hline & \multicolumn{2}{|c|}{$\pi_{t}-\pi_{t}^{*}$ stationary } & \multicolumn{2}{|c|}{$\Pi_{t}-\Pi_{t}^{*}=0$} & & Weak exogeneity & $\begin{array}{l}\text { Strong } \\
\text { exogeneity }\end{array}$ \\
\hline & ADF test $2 /$ & KPSS test 2/ & ADF test & KPSS test & & $\lambda=0$ & $\begin{array}{c}\theta_{1}=\ldots=\theta_{s}=0 \\
\text { given } \lambda=0\end{array}$ \\
\hline Official Core & $\begin{array}{l}N^{* * *} \\
t=-1.79\end{array}$ & $\begin{array}{c}\mathrm{No}^{* *} \\
\mathrm{LM}=0.67\end{array}$ & $\begin{array}{c}\text { Yes } \\
P=0.19\end{array}$ & $\begin{array}{l}\mathrm{No}^{* * *} \\
P=0.00\end{array}$ & $\begin{array}{l}\text { No***} \\
P=0.01\end{array}$ & $\begin{array}{c}\text { Yes } \\
P=0.65\end{array}$ & $\begin{array}{c}\text { Yes } \\
P=0.12\end{array}$ \\
\hline Quah Vahey & $\begin{array}{c}\mathrm{No}^{\star \star * \star} \\
t=-0.97\end{array}$ & $\begin{array}{c}\text { Yes } \\
\text { LM }=0.33\end{array}$ & $\begin{array}{c}\text { Yes } \\
P=0.33\end{array}$ & $\begin{array}{c}N o^{* * *} \\
P=0.00\end{array}$ & $\begin{array}{c}\text { Yes } \\
P=0.23\end{array}$ & $\begin{array}{c}\text { Yes } \\
P=0.65\end{array}$ & $\begin{array}{c}\text { Yes } \\
P=0.21\end{array}$ \\
\hline Trimmed Mean 15L5R & $\begin{array}{l}\text { No*** } \\
t=-1.94\end{array}$ & $\begin{array}{c}\mathrm{No}^{* * *} \\
\mathrm{LM}=0.78\end{array}$ & $\begin{array}{c}\text { Yes } \\
P=0.32\end{array}$ & $\begin{array}{c}\text { Yes } \\
P=0.18\end{array}$ & $\begin{array}{c}\text { Yes } \\
P=0.37\end{array}$ & $\begin{array}{c}\text { Yes } \\
P=0.92\end{array}$ & $\begin{array}{l}\text { No* } \\
P=0.07\end{array}$ \\
\hline Trimmed Mean 20L5R & $\begin{array}{l}\text { No*** } \\
t=-2.11\end{array}$ & $\begin{array}{c}\mathrm{No}^{* *} \\
\mathrm{LM}=0.66\end{array}$ & $\begin{array}{c}\text { Yes } \\
P=0.61\end{array}$ & $\begin{array}{l}N^{* * *} \\
P=0.00\end{array}$ & $\begin{array}{c}\text { Yes } \\
P=0.56\end{array}$ & $\begin{array}{c}\text { Yes } \\
P=0.67\end{array}$ & $\begin{array}{l}\text { No* } \\
P=0.06\end{array}$ \\
\hline Trimmed Mean 25L5R & $\begin{array}{l}\mathrm{No}^{\star * *} \\
\mathrm{t}=-2.21\end{array}$ & $\begin{array}{c}\mathrm{No}^{* *} \\
\mathrm{LM}=0.47\end{array}$ & $\begin{array}{c}\text { Yes } \\
P=0.13\end{array}$ & $\begin{array}{c}N o^{* * *} \\
P=0.00\end{array}$ & $\begin{array}{c}\text { Yes } \\
P=0.78\end{array}$ & $\begin{array}{c}\text { Yes } \\
P=0.47\end{array}$ & $\begin{array}{c}\text { No* } \\
P=0.06\end{array}$ \\
\hline Trimmed Mean 25L10R & $\begin{array}{c}\mathrm{No}^{*} \\
\mathrm{t}=-2.91\end{array}$ & $\begin{array}{c}\text { Yes } \\
\text { LM }=0.17\end{array}$ & $\begin{array}{c}\text { Yes } \\
P=0.35\end{array}$ & $\begin{array}{c}N^{* * *} \\
P=0.01\end{array}$ & $\begin{array}{c}\mathrm{No}^{* *} \\
P=0.05\end{array}$ & $\begin{array}{c}N o^{* * *} \\
P=0.00\end{array}$ & n.a. \\
\hline Persistence Weighted & $\begin{array}{c}N o^{\star * *} \\
t=-0.66\end{array}$ & $\begin{array}{c}\mathrm{No}^{*} \\
\text { LM }=0.39\end{array}$ & $\begin{array}{c}\text { Yes } \\
P=0.21\end{array}$ & $\begin{array}{c}N 0^{* * *} \\
P=0.00\end{array}$ & $\begin{array}{c}\text { Yes } \\
P=0.68\end{array}$ & $\begin{array}{c}\text { Yes } \\
P=0.42\end{array}$ & $\begin{array}{c}N^{* *} \\
P=0.02\end{array}$ \\
\hline Exclusion 3 & $\begin{array}{c}\mathrm{No}^{* * *} \\
t=-0.90\end{array}$ & $\begin{array}{c}\text { Yes } \\
\text { LM }=0.15\end{array}$ & $\begin{array}{c}\text { Yes } \\
P=0.46\end{array}$ & $\begin{array}{c}\text { Yes } \\
P=0.10\end{array}$ & $\begin{array}{c}\mathrm{No}^{* *} \\
P=0.05\end{array}$ & $\begin{array}{c}\text { Yes } \\
P=0.13\end{array}$ & $\begin{array}{c}\text { Yes } \\
P=0.41\end{array}$ \\
\hline Exclusion 6 & $\begin{array}{c}\mathrm{No}^{* * *} \\
t=-1.29\end{array}$ & $\begin{array}{c}\text { Yes } \\
\text { LM }=0.15\end{array}$ & $\begin{array}{c}\text { Yes } \\
P=0.29\end{array}$ & $\begin{array}{c}N o^{* * *} \\
P=0.00\end{array}$ & $\begin{array}{c}N o^{* * *} \\
P=0.00\end{array}$ & $\begin{array}{c}\mathrm{No}^{* *} \\
P=0.02\end{array}$ & n.a. \\
\hline
\end{tabular}

Source: Fund staff estimates

$1 /$ The number of lags in the estimated error correction mechanisms are chosen on the basis of the F-tests for the significance of each lag. A constant is included in each case.

2/ The critical values for the ADF test (model with non-zero constant) are -3.55 at the one percent level, -2.91 at the five percent level, and -2.59 at the ten percent level. The critical values for the KPSS test are 0.74 at the one percent level, 0.46 at the five percent level, and 0.35 at the ten percent level. ${ }^{* * *},{ }^{* *}$, and * represents significance at the one, five, and ten percent, respectively. The number of lags included in the ADF tests is chosen on the basis of the Schartz information critierion. 


\section{CONCLUding ReMARKS}

The usefulness of Sri Lanka's official measure of core inflation for predicting future headline inflation has been the subject of intense debate during most of 2008. This derives from the fact that: (i) the official core measure indicated that underlying inflation was significantly lower than headline inflation; (ii) the central bank has used it in its communications to validate the stance of monetary policy; and (iii) it had been increasing rapidly as the effects of higher food and fuel prices were passed through to other components of the CPI. The purpose of this paper has been to undertake a systematic analysis of the official measure of core inflation and to compare it to other measures of underlying inflation which have been proposed in the literature.

The alternative measures of core inflation analyzed in this paper reveal a wide range for the estimate of underlying inflation in Sri Lanka: at end October 2008, the estimates ranged from 9.0 to 33.6 percent compared to official core inflation of 18.6 percent and headline inflation of 20.2 percent. ${ }^{13}$ While the range is large, the majority of estimates - notably all the nonofficial measures of core inflation during January-June 2008 and an average of more than 60 percent of the measures during July-October 2008 - suggest that underlying inflation in 2008 was above the official measure of core inflation. At the same time, an average of 20 percent of the estimates (more during the first half of 2008) suggest that underlying inflation was above headline inflation at the time. As a result, the majority of the non-official measures of underlying inflation suggest that the official measure of core inflation might have understated inflationary pressures. ${ }^{14}$

The wide range for the estimates of underlying inflation is consistent with the emerging consensus in the literature that the appropriate measure of core inflation depends on its ultimate purpose. Nevertheless, because different methods perform differently across countries and across time, a data driven approach to deciding among the various measures of underlying inflation is appropriate. Consistent with much of the literature, this paper has evaluated a cross-section of the alternative measures of underlying inflation against a set of conditions proposed by Marques et al. (2003) aimed at determining whether or not a particular core inflation measure is: (i) unbiased; (ii) a leading indicator of headline inflation; and (iii) conversely whether headline inflation is not a leading indicator of core inflation.

The results from the statistical tests confirm that the appropriate measure of core inflation depends on its purpose. In particular, the official measure of core inflation and the exclusion 3 measure are leading indicators of headline inflation (but not vice versa) and therefore provide a useful indication of the future path of headline inflation. Several of the measures,

\footnotetext{
${ }^{13}$ The Quah-Vahey estimate of core inflation is available up to September.

${ }^{14}$ This statement needs to be viewed in the context of the emphasis on inflation as the primary concern of monetary policy during the first half of 2008. In the current environment, with the emphasis of monetary policy shifting away from inflation and towards growth, considerations other than expectation of future inflation will influence the monetary policy stance.
} 
however, including the official measure of core inflation and some of the trimmed mean measures were neither cointegrated with headline inflation nor unbiased.

Overall, our findings suggest that the official measure of core inflation in Sri Lanka does contain some useful information about the future path of headline inflation. However, our results also suggest that using the official measure of core inflation (as it currently stands) may be inadequate as a communication tool because of its apparent biasedness with respect to headline inflation. The ongoing work at the Central Bank to develop new measures of core inflation is therefore appropriate and should be high on the agenda.

The results in this paper yield some additional insights. Firstly, the range among different measures - including those that the statistical tests suggest are leading indicators of headline inflation-has at times been large. This was particularly true during the recent run-up in fuel and food prices with the official core measure suggesting that underlying inflation was substantially lower than most of the alternative measures of core inflation. The gap between the official core measure and the alternative measures essentially reflected differences in assumption about the persistence of the run-up in commodity prices and the extent to which these would feed through into the rest of the CPI basket. While it is not the purpose of this paper to speculate on the extent to which this happened, the recent history in Sri Lanka demonstrates the degree of uncertainty surrounding the measurement of underlying inflation and that the appropriate measurement is unlikely to remain constant over time. A suite of core inflation measures that can be continuously updated and statistically evaluated would therefore be helpful. As noted previously, this is consistent with the recommendations from numerous authors, including Silver (2007) who notes that: "If the resulting measures give similar results, then they should give some confidence to the monetary authorities in making decisions based on such measures. If they do not, differences in the nature of the measures used should, by construction, allow for insights into the inflationary process". 


\section{References}

Blinder, Alan S., 1997, "Commentary for 'Measuring Short-Run Inflation for Central Bankers'," Federal Reserve Bank of St. Louis Review, Vol. 79 (May/June), pp. 157162.

Bryan, Michael F. and Stephen G. Cecchetti, 1993, "The Consumer Price Index as a Measure of Inflation”, Federal Reserve Bank of Cleveland Economic Review, Vol. 29 (Quarter 4), pp. 15-24.

Cecchetti, Stephen G., 1997, "Measuring Short-Run Inflation for Central Bankers”, Federal Reserve Bank of St. Louis Review, Vol. 79 (May/June), pp. 143-156.

Central Bank of Sri Lanka, 2008, Monetary Policy Review, July. Available via Internet: http://www.cbsl.gov.lk/pics_n_docs/02_prs/_docs/press/press_20080716e.doc

_ 2008, Monetary Policy Review, April. Available via Internet: http://www.cbsl.gov.lk/pics_n_docs/02_prs/_docs/press/press_20080423e.doc

Cutler, Joanne, 2001, “A New Measure of Core Inflation in the U.K.”, MPC Unit Discussion, Paper No. 3 (London: Bank of England).

Eckstein, O., 1981, Core Inflation (Englewood Cliffs, New Jersey: Prentice-Hall).

Engle, Robert F. and Clive W. J. Granger, 1987, "Cointegration and Error-Correction: Representation, Estimation, and Testing", Econometrica, Vol. 55, pp. 251-276.

Freeman, D.G., 1998. "Do core inflation measures help forecast inflation?" Economics Letters, Vol. 58, pp. 143-147.

Ginting, Edimon, 2007, "Is Inflation in India and Attractor of Inflation in Nepal?" IMF Working Paper 07/269 (Washington: International Monetary Fund).

Heath, Alexandra, Ivan Roberts, and Tim Bulman, 2004, "Inflation in Australia: Measurement and Modeling", in The Future of Inflation Targeting, ed. by Christopher Kent and Simon Guttmann (Sydney: Reserve Bank of Australia)/

Kearns, J, 1998, “The Distribution and Measurement of Inflation”, Research Discussion Paper No. 9810 (Sydney: Reserve Bank of Australia).

Kwiatkowski, Denis, and others, 1992, "Testing the Null Hypothesis of Stationarity against the Alternative of a Unit Root", Journal of Econometrics, Vol. 54, pp. 159-178.

Lafléche, T, 1997, "Statistical Measures of the Trend Rate of Inflation”, Bank of Canada Review (Autumn), pp. 29-47.

Lehohla, Pali J., and Annette Myburgh, 2002, "Statistical Implications of Inflation Targeting in South Africa", in Statistical Implications of Inflation Targeting: Getting the Right Numbers and Getting the Numbers Right, ed. by C. Carson, C. Enoch, and C. Dziobek (Washington: International Monetary Fund).

Le Bihan, H., Sédillot, F., 2000, "Do Core Inflation Measures help Forecast Inflation? Outof-Sample Evidence from French Data", Economics Letters, Vol. 69, pp. 261-266.

Macklem, Tiff, 2001, “A New Measure of Core Inflation”, Bank of Canada Review, (Autumn), pp. 3-12. 
Mankikar, Alan, and Jo Paisley, 2004, "Core Inflation: A Critical Guide", Working Paper No. 242, Summary in Bank of England Quarterly Bulletin, Vol. 44 (Winter), p. 466.

Marques, Carlos Robalo, Pedro Duarte Neves, and Lu1's Morais Sarmento, 2003, "Evaluating Core Inflation Indicators", Economic Modeling, Vol. 20 (July), pp. $765-775$.

— , 2000, "Evaluating Core Inflation Indicators", Economic Research Department Working Paper No. 3-00 (Lisbon: Banco de Portugal).

Quah, Danny, and Shaun P. Vahey, 1995, "Measuring Core Inflation”, Economic Journal, Vol. 105 (September), pp. 1130-1144.

Roger, Scott, 2000, "Relative Prices, Inflation and Core Inflation", IMF Working Paper 00/58, (Washington, International Monetary Fund).

_ , 1998, "Core Inflation: Concepts, Uses and Measurement", Reserve Bank of New Zealand Discussion Paper No. G98/9.

_ 2000, "Relative Prices, Inflation and Core Inflation", IMF Working Paper 00/58, (Washington, International Monetary Fund).

Silver, Mick, 2007, "Core Inflation: Measurement and Statistical Issues in Choosing Among Alternative Measures", IMF Staff Papers, Vol. 54, No. 1.

Wynne, Mark A. 2008. "Core inflation: A Review of Some Conceptual Issues", Federal Reserve Bank of St. Louis Review (May), pp. 205-228. 